\title{
INPUT TYPE EFFECTS ON STUDENTS' WRITTEN NARRATIVE RESPONSES
}

\author{
Mohd Izwan Ramlee' \\ Ernisa Marzuki² \\ Ahmed Shamsul Bahri Mohamad Tuah ${ }^{3}$ \\ 'Universiti Teknologi MARA Kampus Kota Samarahan \\ ${ }^{2}{ }^{3}$ Centre for Language Studies, Universiti Malaysia Sarawak \\ 1 mohdizwanramlee@gmail.com \\ ${ }^{2}$ mernisa@cls.unimas.my \\ ${ }^{3}$ mtasbahri@cls.unimas.my
}

\begin{abstract}
This pilot study examines the differences of second language learners' written responses when they are given two different input types with similar content. One input was through written narrative or visual only input, where the learners need to read, and the other was a performed narrative or audio-visual input, where learners need to watch. Learners were then required to respond to the input by completing the narratives. Results showed that there were no major discrepancies in terms of complete/incomplete storylines, length, and number of dialogues, but revealed that the audio-visual input influenced learners more as their responses have a stronger correspondence to the traits in the performance rather than the written narrative.
\end{abstract}

Keywords: input, written narrative, drama performance, second language learner

\section{Introduction}

There are undoubtedly many methods to teach a language. These methods can vary in the forms of input type, which in turn may affect learner response. For instance, Morrow (1988) found that young children who often listen to story readings are better in responding and asking questions compared with those who do not. Narratives is one type of input for language teaching. Narratives can be in written form (reading text), audio form (stories that are listened to), or audio-visual form (e.g., drama, play).

Drama has been extensively used in classroom teaching. Belliveau's (2007) study on a drama-based approach to teaching showed that learners found drama to be a fun way of learning. Students were also found to be more motivated to learn. Belliveau, however, only examined student and teacher responses when performing a drama and not their responses whilst watching a drama. Still, it gives the idea that the insertion of drama into language teaching and learning can be beneficial to both teachers and students. One teacher was quoted as saying, "My teaching style was ... greatly affected ... from talents that I never knew I had" (p. 58). Belliveau's (2007) study showed a similar result with Bernal's (2007) study. Bernal (2007) also used drama to teach English to second language learners with positive results. 
Nevertheless, it should be noted that drama may not always work in a language classroom. Dodson (2000) points out some possible problems of using drama in classrooms, which may include student's scepticism and the perception that drama is not serious learning. Wan (1990) warns that using drama in a language classroom may encourage the use of inaccurate linguistic forms. In addition, it may also not be suitable for all levels of learners.

An alternative to drama is the use of printed stories or narratives. As stories are entertaining, believable and easier to remember compared to formulae or rules, they are perceived as an effective teaching tool (Rossiter, 2002). Not only can stories be used in adult and/or young adult education, they have also been found to be effective with children (Morrow, 1988). Nonetheless, Squire (1964) cautioned educators to be aware of the difficulties. The study examined 52 adolescents reading four different short stories. Squire found six sources of difficulty which may hinder understanding of the texts. The six sources were: 1) failure to grasp author's intentions; 2 ) reliance on stock responses during certain situations; 3) possession of certain critical pre-notions; 4) sidetracked by irrelevant matters; 5) determination to interpret story in only one way; and 6) being "happiness bound".

Insofar, research on learner responses to drama and narratives have focused on direct student participation (e.g., Belliveau, 2007; Bernal, 2007; McQuiggan, Rowe, Lee, \& Lester, 2008; Stern, 1980; Vitz, 1984). When involved in drama, Stern (1980) found that learners felt that they gained higher self-confidence as they became less embarrassed to speak out. In addition, the learners in Stern's (1980) research also revealed that they enjoyed participating in a drama. Similarly, research indicated that learners reported higher levels of interest when narratives were applied in the form of a computer game (McQuiggan, Rowe, Lee, \& Lester, 2008).

These studies indicate that learners seem to respond positively towards the use of drama and narratives in classroom context. However, the use of drama versus written narratives as input for language teaching has not been widely researched. This pilot study focuses on how learners respond to these two forms of narrative input, namely, performed narrative (short drama - audio-visual) and written narrative (short story - visual only).

\section{Purpose of Study}

The preliminary study examined the output generated by university learners after exposure to two different input types: visual (printed text) and audio-visual presentation (short drama). It aims to find out whether the different input types affect the learners' responses despite the similarity of the input context.

1. Are there any differences in the learners' written responses to visual and audiovisual input?

2. Which input (visual or audio-visual) is more influential when presented first?

\section{Methodology}

Two types of input were prepared by the researchers. One was a written input (visual only), which was a typed story (see Appendix A). The second was a short drama performance for the audio-visual input. The drama performance mimicked the written storyline with six minor differences. The differences are:

i. The name of the main characters (Samuel and Maria in the visual input; Sam and Nisa in the audio-visual input); 
ii. The number of years that the characters have been together (two years in the visual input and four years in the audio-visual input);

iii. The place where the female character finds a hair (coat in the visual input and pillow in the audio-visual input);

iv. The name of the woman with whom the main male character allegedly has an affair with (not mentioned in the visual input; Caroline in the audio-visual input);

v. The name of the man with whom the main female character has an affair with (not mentioned in the visual input; Faidz in the audio-visual input); and

vi. The animal whose hair was found (a dog in the visual input and a cat in the audiovisual input).

The drama was performed by two instructors of English in a public university. Both types of input served as a prompt as learners were required to continue the story presented in the visual and audio-visual inputs.

Seven learners from two groups of intact classes (14 altogether) were randomly selected. All 14 learners were of intermediate level of English proficiency. The learners were then grouped into Group A and Group B. Group A received the audio-visual input first before given the visual input, whilst Group $B$ received the visual input first before the audio-visual input. This counterbalancing is shown in Table 1.

Table 1

Counterbalancing of input for Groups $A$ and $B$

\begin{tabular}{lll}
\hline Group & First input & Second input \\
\hline A & Audio-visual & Visual \\
B & Visual & Audio-visual \\
\hline
\end{tabular}

For the visual input, the learners were given a piece of paper containing the typed story and approximately 10 minutes to read. Then the papers were taken away from them and they were given another 10 minutes to continue the story. No reference to the typed story was allowed once they started writing their responses. Hence, the responses were solely based on the learners' understanding and memorisation of the visual input in the given time.

Table 2

Codes of responses from learners

\begin{tabular}{ll}
\hline Group A (watch first; read second) & Group B (read first; watch second) \\
\hline Response A1 = seven responses & Response B1 = seven responses \\
Audio-visual (drama) & Visual (reading) \\
Response A2 = seven responses & Response B2 = seven responses \\
Visual (reading) & Audio-visual (drama) \\
\hline
\end{tabular}

For the audio-visual input, both groups were combined to watch a 10-minute performance about a similar storyline. The group combination was done to ensure that all learners watched the same performance, as no live performance can be replicated exactly. An even slightly different performance would most probably affect the learners' responses. After the performance, the learners were instructed to respond by continuing the story that was performed, also through writing. Four types of responses - coded A1, A2, B1 and B2 - 
were gathered from the 14 learners. Altogether, there were 28 responses, as presented in Table 2 .

\section{Findings and Discussion}

\section{Differences in responses from audio-visual input and visual input}

The learners' responses were first analysed individually to find differences. Three criteria were analysed: the number of incomplete storylines, the length of stories, and the number of dialogue lines found in the stories. The results are shown in Table 3.

Table 3

Findings based on responses from Group A and Group B

\begin{tabular}{lllll}
\hline & Group A & \multicolumn{3}{c}{ Group B } \\
\cline { 2 - 5 } & A1 & A2 & B1 & B2 \\
\hline Incomplete stories & 2 & 2 & 3 & 4 \\
Approximate number of words & 1,308 & 1,361 & 1,060 & 1,231 \\
Number of dialogue lines & 13 & 16 & 29 & 28 \\
\hline
\end{tabular}

The first criterion analysed was whether learners completed their stories upon submission. Table 3 shows that there was almost no difference in the number of incomplete storylines. The lack of differences in the number of incomplete stories suggested that there was no significant difference when the input was given through visual form only or through audio-visual form. Nonetheless, this result might also be due to the time given by the researcher to the learners -10 minutes to complete their responses. Perhaps 10 minutes was not enough for some learners regardless of the type of input. This may be interpreted in a few ways: the learners might lack ideas to complete their stories, or did not fully understand the input, or had miscalculated the given time for writing the response. Lack of proficiency, however, was not one of the causes as all 14 learners' English proficiency levels were similar.

Analysis regarding the length of the responses showed that responses from Group A were lengthier than responses from Group B. Further analysis revealed that Group A produced more words after reading the typed input, whilst Group B produced more words after watching the drama. Nonetheless, when the numbers are combined, it is clear that the group who watched the drama produced a higher number of words compared to the group reading the narrative. The difference, however, was very small (118 words). This slightly higher number of words in responses written after watching the performance may be due to the more dramatic nature of presentation. It can be argued that drama, as Belliveau (2007) found, motivates the learners to write more. Worthy of note is the fact that the number of words did not correspond to the completion (or non-completion) of storylines, as shown in Group B's responses (see Table 3).

The third analysis involved the number of dialogue lines. A dialogue line is considered as any fully quoted phrase or sentence said by any character in the learners' responses. The results for the number of dialogue lines were found to be the opposite to the results for the number of words, as Group B produced a higher number of dialogue lines compared to Group A, for both visual and audio-visual input. This is most probably the reason that Group B had fewer words; their responses were narrated in terms of dialogues. 
Interestingly, responses from both groups contained more dialogue lines after reading the the text instead of after watching the performance. The researchers initially expected a higher number of dialogue lines to emerge in responses to the drama performance as the reading text contained less dialogue than the performed act. This result might be due to the fact that the learners involved were currently learning to write scripts, and at the time the research was conducted, they had not yet acted their scripts out.

\section{Influence of the input type}

To find out the influence yielded by each input type, the researchers compared the learners' responses by concentrating on the six minor differences mentioned earlier (name; number of years; place; name of male affair; name of female affair; type of animal). Responses coded as A1 (audio-visual: first) were compared with responses coded as B2 (audio-visual: second), whilst responses coded as A2 (visual only: second) were compared with responses coded as B1 (visual only: first).

It was found that $\mathrm{A} 1$ and $\mathrm{B} 2$ responses did not deviate from the original drama performance, at least, in the case of the six differences. Therefore, learners who watched the drama performance after reading the input were not influenced by their reading. On the other hand, A2 and B1 responses were dissimilar. Stories written by learners who read the input first before they watched the performance contained no deviations from the original written input, but stories written by learners who read the input after they watched the performance showed deviations. Thus, learners who received audio-visual input before they received visual only input tended to be influenced by the audio-visual input even when they responded to the visual only input.

As expected, drama as an input seemed to have more influence on learners' responses. Even though the learners were given a short break between watching the drama and reading, they were still influenced by the characters and scenes in the drama. This is evident from the existence of names of characters (Ernisa instead of Maria), the insertion of names which were mentioned in the drama but not in the reading input (e.g., Carol) and the "wrong" type of animal (cat instead of $d o g$ ).

Another interesting finding from this study was the response from one particular learner. This learner, who was in Group B (reading first before watching the drama), did not seem to understand the written input. This was clear from the way the learner wrote his/her response. The story that $\mathrm{s} /$ he submitted was incoherent to the original input. However, after watching the drama, the same learner managed to continue the story coherently. This finding seemed to support Squire (1964) who ascertained that narratives alone may not be understood by learners. In this case, the narrative was the typed story. The learner in this study was able to understand the same narrative when it was performed.

Finally, it can be argued that with the different inputs, there were also different instructional tasks, as the instruction for the visual input was "Read the exposition and continue the story", whilst the instruction for the audio-visual input was "Watch the performance and continue the story". Nevertheless, the researchers believe that the differences noted in the analysed responses are more likely to be the results from the different input types and less likely the result of the instructional tasks.

\section{Conclusion}

This pilot study analyses the differences found when learners continued a story from two different inputs - visual input only (reading) and audio-visual input (drama). The study also 
looks at the influence of one type of input against the other. It was found that there are slight differences between the responses when learners read the input and when the learners watch the input. These differences are in terms of the number of words, which is higher in the responses from watching the drama and the number of dialogue lines, which is higher in responses from reading. The study also found that drama as an input may be more influential compared with reading text as an input. The preliminary findings need to be verified in further studies using a larger number of participants.

\section{References}

Belliveau, G. (2007). An alternative practicum model for teaching and learning. Canadian Journal of Education, 30(1), 47-67.

Bernal, P. (2007). Acting out: Using drama with English learners. The English Journal, 96(3), 26-28.

Dodson, S. L. (2000). FAQs: Learning languages through drama. Texas papers in Foreign Language Education, 5(1), 129-141.

McQuiggan, S. W., Rowe, J. P., Lee, S., \& Lester, J. C. (2008). Story-based learning: The impact of narratives on learning experiences and outcomes. In Proceedings of the 9th International Conference on Intelligent Tutoring System (pp. 530-539). Berlin, Heidelberg: Springer-Verlag.

Morrow, L. M. (1988). Young children's responses to one-to-one readings in school settings. Reading Research Quarterly, 23(1), 89-107.

Rossiter, M. (2002). Narrative and stories in adult teaching and learning. Retrieved from http://calpro-online.org/eric/docs/dig241.pdf.

Squire, J. R. (1964). The responses of adolescents while reading four short stories. National Council of English Teachers Research Report 2: Champaign.

Stern, S. L. (1980). Why drama works: A psycholinguistic perspective. In J. W. Oller, Jr., \& P. A R. Amato (Eds.), Methods that work: A smorgasbord of ideas for language teachers (pp. 207-225). Rowley: Newbury House Publishers Inc.

Wan, Y. S. (1990). Drama in teaching English as a second language - A communicative approach. The English Teacher, 19. Retrieved from http://www.melta.org.my/ET/ 1990/main8.html.

Vitz, K. (1984). The effects of creative drama in English as a second language. Children's Theatre Review, 33(2), 23-26. 